\title{
Equidad educativa interna y externa: principales tendencias en Argentina durante las últimas décadas
}

\author{
Internal and External Educational Equity: Main \\ Trends in Argentina during the last decades
}

Natalia Krüger*

\section{RESUMEN}

El sistema educativo argentino ha sido desde los años noventa escenario de profundas transformaciones, como resultado de las medidas de reforma aplicadas en medio de grandes cambios en el contexto socioeconómico. Durante este periodo se han destinado niveles crecientes de recursos al sector educativo, con el objetivo de incrementar el acceso de toda la población a una educación de calidad. A través del análisis de diversos indicadores de cobertura y desempeño del sistema educativo y del mercado laboral, el presente trabajo pretende evaluar cómo han evolucionado en el país los niveles de equidad educativa interna y externa. Es decir, interesa estudiar en qué medida las trayectorias educativas son condicionadas por las desigualdades preexistentes, y en qué medida la educación está contribuyendo a reducir (o reproducir) las desigualdades en el futuro. La conclusión general es que más allá de los progresos registrados en el acceso y el perfil educativo de la población, aún existen importantes deudas pendientes. Los resultados internos, desde un punto de vista cualitativo, continúan distribuyéndose inequitativamente en función del origen social. Luego, las restricciones en el mercado de trabajo obstaculizan el potencial de la educación para cerrar las brechas socioeconómicas iniciales.

Palabras clave: equidad, educación básica, Argentina

\section{ABSTRACT}

The Argentine educational system has been deeply transformed since the nineties as a result of the reforms implemented in the midst of great changes in the socioeconomic context. During this period, increasing levels of resources have been allocated to the education sector with the goal of providing quality education for all. Through the analysis of several coverage and outcome indicators, this article aims to evaluate the evolution of the levels of internal and external educational equity in the country. That is, it seeks to assess the extent to which educational careers are conditioned by pre-existing inequalities, and the extent to which education is helping to reduce (or reproduce) inequalities in the future. The overall conclusion is that beyond the progress made in terms of access and the educational profile of the population, significant debts remain. From a qualitative point of view, internal results continue to be unequally distributed according to social origin. Also, labor market restrictions hinder the potential of education to bridge the initial socioeconomic gaps.

Key words: equity, basic education, Argentina

"Departamento de Economía (Universidad Nacional del Sur), Instituto de Investigaciones Económicas y Sociales del Sur (UNS-CONICET), Argentina; natalia.kruger@uns.edu.ar 


\section{INTRODUCCIÓN}

La segunda de las Metas Educativas 2021, aprobadas en 2010 por la Conferencia Iberoamericana de Educación - "Lograr la igualdad educativa y superar toda forma de discriminación en la educación"-, da cuenta tanto de la importancia asignada a este objetivo en la región, como de las persistentes dificultades enfrentadas para alcanzarlo.

El valor intrínseco de la educación, junto a su potencial para favorecer el desarrollo social y garantizar el cumplimiento de otros derechos, explican el interés por promover y estudiar la equidad educativa. Ahora bien, cada vez resulta más evidente que "Al mismo tiempo que la educación está en la base del desarrollo equitativo, la educación requiere de una base de equidad para poder desarrollarse" (Tedesco, en el Prólogo a Feijoo, 2002: 8).

Así, el estudio de la equidad educativa puede abordarse desde dos enfoques interrelacionados: la equidad educativa interna y la equidad educativa externa (Calero y Bonal, 1999). La primera dimensión remite a la influencia de los condicionantes socioeconómicos en el seno del sistema educativo. La segunda, se encuentra ligada al valor instrumental de la educación y remite a sus efectos de más largo plazo sobre objetivos de desarrollo individual y social.

El anhelo por alcanzar un grado satisfactorio de equidad educativa, que a su vez pueda promover la equidad social en un sentido más amplio, es de larga data. Sin embargo, la evidencia empírica indica que las políticas implementadas hasta ahora no han logrado revertir las causas históricas de la desigualdad. Es más, los sistemas educativos podrían incluso estar reforzando los factores de inequidad iniciales (Rodríguez, 2002).

Como en otros países, durante las últimas dos décadas Argentina ha sido escenario de profundas transformaciones en el sector educativo, fruto de la aplicación de nuevas políticas y de los cambios registrados en los planos económico, social, político, y cultural. Resulta de interés, por lo tanto, evaluar cómo ha evolucionado en este marco el vínculo entre la educación y la equidad.

El objetivo del presente trabajo es analizar empíricamente la evolución de ambas dimensiones de la equidad educativa durante las últimas décadas en el país, destacando los principales logros 
y desafíos pendientes. Para ello, se presentan estadísticas e indicadores relativos al funcionamiento del sistema educativo, interpretándolos a la luz de los cambios acaecidos tanto en su interior como en el contexto en el que se encuentra inmerso.

Cabe aclarar que el estudio se focaliza en la educación básica -primaria y secundaria- formal, y especialmente en el nivel medio, por ser el que sufrió transformaciones más radicales durante este periodo.

A continuación, se define el marco teórico-conceptual de la investigación. Luego, la tercera sección describe las tendencias registradas en la equidad educativa interna y externa desde los años noventa hasta la actualidad, procesando información secundaria de diversas fuentes. Por último, se elaboran las conclusiones de la investigación.

\section{EDUCACIÓN Y EQUIDAD: MARCO TEÓRICO-CONCEPTUAL}

\section{El concepto de equidad}

Proveniente del latín aequitas, la palabra equidad significa igual y puede asociarse a diversas definiciones (Formichella, 2011a). Desde un punto de vista general, Baker y sus colaboradores (2004) postulan que la equidad es una relación de algún tipo entre personas o grupos, respecto a algún aspecto de sus vidas. Esto da lugar a diversas preguntas, como ¿qué tipo de relación?, ¿equidad entre quiénes? (Young, 2001) y ¿equidad de qué? (Sen, 1979).

Asimismo, resulta esclarecedor el desarrollo de López: la equidad es una "instancia que se ubica por encima del análisis de la igualdad en las distintas dimensiones de la vida humana, organizándolas y estructurándolas en torno a una igualdad fundamental. Establecer un criterio de equidad significa identificar cuál es la dimensión fundamental respecto a la cual definir un horizonte de igualdad, y en torno a la cual se estructuran todas las desigualdades resultantes" (2006: 67). La elección de esta igualdad fundamental es política e implica una valoración ética. Por ende, la equidad social no tiene un único significado.

Distintas teorías de la justicia social han elaborado respuestas diversas a la pregunta acerca de cuál es la métrica igualitaria más 
apropiada (o ¿igualdad de qué?). ${ }^{1}$ Considerando que la intención de este trabajo es relacionar la equidad social con la educación, parece apropiado adoptar un criterio de justicia que reconozca la relevancia de las circunstancias exógenas. De esta forma, se apoya en las referencias de un grupo de teorías que define la equidad social como aquella situación en la que se igualan las oportunidades de las personas. Esta corriente comprende los enfoques de "capacidades básicas" de Sen (1979), de "alisar el camino" de Roemer (1998), de "oportunidades para el bienestar” de Anderson (1999) y de "acceso a las ventajas" de Cohen (1989). Sin adoptar uno de ellos en particular, se pretende enfatizar un punto en común central: tanto la disponibilidad de recursos como la posibilidad de beneficiarse de los mismos para el logro de ciertos fines se ven afectadas por factores idiosincrásicos que suelen estar fuera del control individual. Avanzar hacia un mayor grado de equidad social requiere minimizar estas influencias.

Ahora bien, al considerar la igualdad de oportunidades en el ámbito educativo, es necesario realizar nuevas precisiones. Una situación de equidad educativa se relaciona con la superación de los determinismos sociales en el tránsito por el sistema escolar (equidad interna) y con un rol positivo de la educación en la igualdad posterior (equidad externa), según la conceptualización de Calero y Bonal (1999).

Así, entran en juego distintas instancias del sistema educativo y de su relación con el entorno socioeconómico, cada una de las cuales es susceptible de medición a través de diversos indicadores. Puede tenerse en cuenta la equidad en el acceso, en las condiciones o medios de aprendizaje, en los logros o resultados, y en la realización social de esos logros (Demeuse, en López, 2006). La meta de igualar las oportunidades en cada dimensión puede requerir la aplicación de políticas de discriminación positiva, que instalen desigualdades en ciertos aspectos para compensar las desventajas iniciales (Haretche, 2013).

Por otra parte, frente a la pregunta de ¿igualdad entre quiénes?, se hace necesario definir algún atributo de referencia para realizar comparaciones entre grupos. Aquí se contemplará a los grupos de distinto nivel socioeconómico (NSE), dejando de lado

\footnotetext{
${ }^{1}$ Un resumen de las mismas puede encontrarse en Formichella (2011a) o en Haretche (2013).
} 
otros anclajes sociales como el género, la etnia, la zona de residencia o la nacionalidad.

\section{La retroalimentación entre la equidad social y la equidad educativa}

La equidad educativa se vincula con la equidad socioeconómica a través de múltiples vías. En primer lugar, la equidad en el ámbito educativo es un elemento constitutivo de la equidad social, debido al valor intrínseco de la educación. La misma es ampliamente reconocida como un derecho humano fundamental, crucial para la formación de la identidad y la transmisión de valores y conocimientos, con incidencia directa en el bienestar. Al mismo tiempo, la educación posee un valor instrumental, ya que posibilita y potencia el acceso a otros derechos y recursos, promoviendo una plena participación económica, social y cultural (Baker et al., 2004).

En este sentido, la literatura económica ha analizado profusamente los efectos de la educación sobre el bienestar. Desde un enfoque individual, se ha ocupado de estudiar sus retornos en términos de las condiciones laborales o los ingresos. Tanto teórica como empíricamente, numerosos estudios han identificado una asociación positiva entre la escolarización -en cantidad y en calidad- y la posición económica personal (Heckman, Lochner y Todd, 2006; Hanushek y Wößmann, 2008, etc.). A su vez, hay evidencia acerca de importantes beneficios no monetarios de la educación (Formichella, 2011b).

Desde una óptica agregada, existe consenso acerca de que los retornos sociales de la educación pueden incluso superar a los privados, dada la influencia que tiene en el crecimiento económico y en el desarrollo social y cultural. La distribución equitativa de la educación tiene el potencial para promover la movilidad social ascendente, la igualdad de ingresos, los valores democráticos y la cohesión social.

Entonces, el valor intrínseco e instrumental de la educación implica que la igualdad de oportunidades en este plano es imprescindible para equiparar las oportunidades de vida en un sentido más amplio. Esto representa la dimensión externa de la equidad educativa. 
Desde el punto de vista inverso, es claro que la equidad en el ámbito educativo depende en gran medida del grado de equidad existente en el entorno socioeconómico en el que se inscribe. Las desigualdades culturales, económicas, raciales o de género condicionan las oportunidades de los individuos dentro del sistema educativo, si bien su influencia puede ser más o menos intensa en cada lugar.

Teóricamente, la intensidad reconocida a la relación entre la equidad educativa y socioeconómica depende de la postura adoptada acerca de la función social de la educación.

En principio, encontramos un enfoque optimista en las corrientes funcionalistas -entre las que se ubica la moderna Teoría del Capital Humano, desarrollada en los años sesenta por Schultz (1960), Becker (1964) y Mincer (1958) - que conciben la educación como una herramienta de movilidad social ascendente y como un factor clave del desarrollo económico y social (Bonal, 1998). Según esta teoría, la equidad interna estaría determinada por las preferencias, las capacidades y los esfuerzos individuales, constituyendo la educación un mecanismo neutro para la asignación de posiciones sociales.

Especialmente a partir de los ańos setenta, este paradigma comenzó a recibir críticas sistemáticas (Bonal, op. cit.). Por un lado, surgieron otros enfoques provenientes de la Economía que destacan la función selectiva de la educación frente a la cualificadora. Aquí encontramos la hipótesis del credencialismo (Spence, 1973; Arrow, 1973), la teoría de "la fila" de Thurow (1972), y las teorías de la segmentación del mercado de trabajo (Reich, Gordon, y Edwards, 1973). Según estos análisis, la educación funcionaría principalmente para solucionar un problema de información o posicionarse mejor en el mercado laboral.

Por otro lado, en esta época se afianzó un nuevo paradigma que sostiene que la función social de la escuela no es reducir sino reproducir las desigualdades preexistentes. Distintos autores desde la Sociología de la Educación desarrollaron teorías "crítico-reproductivistas" (Saviani, 1983) postulando la imposibilidad de comprender la educación si no es a partir de sus condicionantes sociales, y señalando que su función básica es legitimar la estructura social. ${ }^{2}$

\footnotetext{
${ }^{2}$ En Rivero (2002) se sintetizan los aportes más representativos de esta corriente.
} 
Todas estas teorías han realizado aportes valiosos, ofreciendo un conjunto de herramientas para interpretar los sistemas educativos y su relación con el entorno, a la vez que enfrentan diferentes críticas (Saviani, op. cit.; Bonal, 1998). Entre el optimismo de las corrientes funcionalistas y el determinismo de las crítico-reproductivistas, existen planteamientos superadores que reconocen el potencial transformador de la educación para configurar un proceso de emancipación personal y colectivo (Rivero, 2002).

En la práctica, el grado de equidad educativa interna y externa puede variar según el momento o el contexto analizado, y dentro de un mismo sistema puede haber mecanismos que tiendan a reducir las desigualdades, al tiempo que otros las reproducen o amplían.

Así, la posibilidad de que un país ingrese en una senda de desarrollo más equitativo mejorando el perfil educativo de su población depende de múltiples procesos interrelacionados, como la calidad de la educación impartida, las características del mercado laboral y la calidad institucional, entre otros (DeFerranti et al., 2004).

Por otro lado, los sistemas educativos difieren significativamente en el grado en que las circunstancias sociales condicionan los logros (OCDE, 2010; UNESCO, 2010). Distintos procesos endógenos -como la gobernabilidad, la calidad institucional, las políticas de selección y agrupamiento de alumnos, o los recursos destinados- actúan como mediadores en la relación entre la equidad social y la educativa.

Para resumir, aquí se consideran diversos aspectos de la equidad educativa, entendida como la igualdad de oportunidades para grupos de distinto NSE (Figura 1). En su dimensión interna, se contempla el impacto de las circunstancias en el acceso, el tratamiento dentro del sistema y los resultados internos. En su dimensión externa, se evalúa la capacidad de la educación para influir positivamente en las trayectorias laborales y sociales posteriores, reduciendo la desigualdad en dichos resultados. 
REVISTA LATINOAMERICANA DE ESTUDIOS EDUCATIVOS, VOL. XLVI, NÚM. 2, 2016

FIGURA 1. Dimensiones y aspectos de la equidad educativa

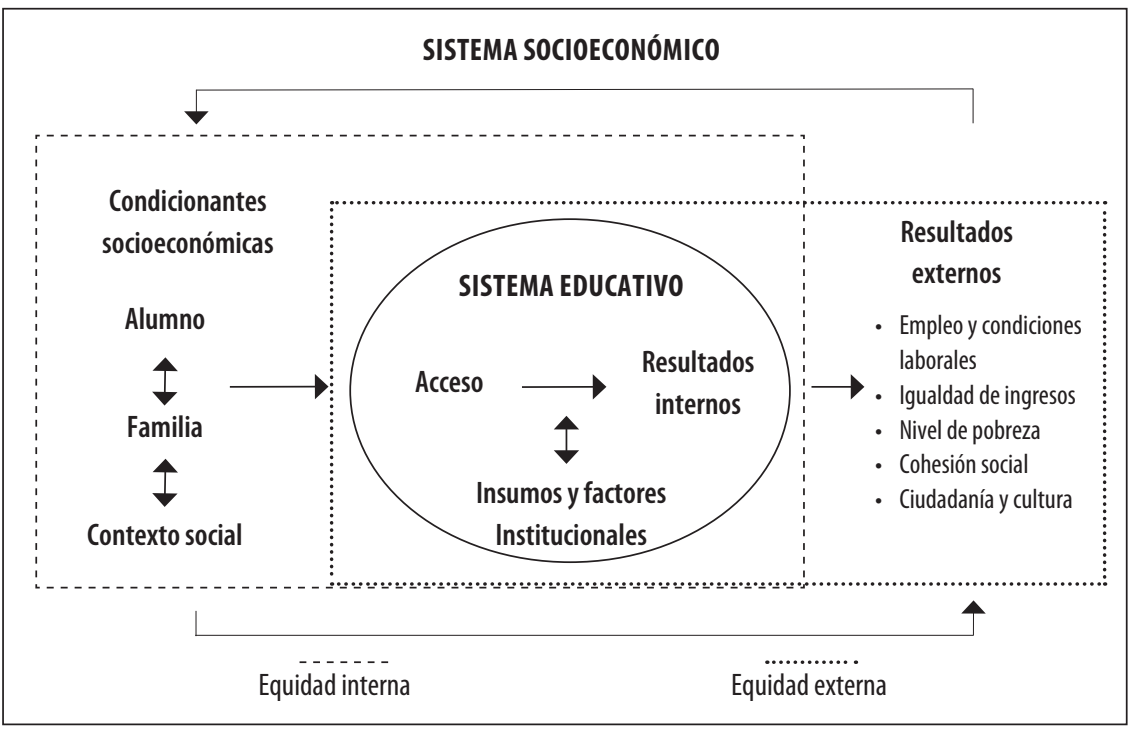

\section{TENDENCIAS EN ARGENTINA DURANTE LAS ÚLTIMAS DÉCADAS}

El énfasis puesto en esta etapa se justifica por las múltiples y profundas transformaciones que han experimentado la economía y la sociedad argentinas desde los años noventa. El sistema educativo no se ha encontrado ajeno a estos procesos, y ha sido objeto de una amplia reestructuración.

A modo introductorio, cabe mencionar que la Argentina se rige por un sistema federal de gobierno y una organización descentralizada del sistema educativo: las provincias son responsables de administrar y proveer la educación básica, mientras que el gobierno nacional se encarga del sistema universitario. Además de la gestión estatal, se reconoce el derecho a la prestación de servicios a agentes privados. La educación es obligatoria en todo el país desde la edad de cinco años hasta la finalización de la escuela secundaria. 
La configuración actual del sector educativo es el resultado de innumerables cambios ocurridos desde su etapa fundacional a fines del siglo XIX. Hacia inicios de los noventa, la educación argentina había acumulado grandes logros, pero aún enfrentaba importantes desafíos. Cervini y Tenti Fanfani (2005) sostienen que los diagnósticos educacionales en ese momento indicaban que el acceso, el ingreso tardío o el abandono en el nivel primario se encontraban en vías de resolución a corto plazo - de hecho, se estaba muy cerca de lograr el horizonte de cobertura universal en este nivel-. Sin embargo, la repetición y los bajos aprendizajes representaban un serio problema. En el caso del nivel medio, el acceso y la deserción resultaban mucho más problemáticos. Comenzaba a perfilarse la universalización en los niveles postprimario como nuevo objetivo de política, cuestión que resultó central en las reformas educativas de las décadas subsiguientes.

\section{El contexto socioeconómico}

Luego de que la década de los ochenta culminara con una crisis macroeconómica en la que se destacaron dos episodios de hiperinflación, la nueva administración instauró un paradigma político e institucional que señalaba como ideal una economía de mercado, plenamente integrada al mundo y con estricta disciplina fiscal. A través de un profundo y veloz proceso de reformas de corte neoliberal, se logró en los noventa recuperar la estabilidad macroeconómica y entrar en una senda de fuerte crecimiento. Sin embargo, el modelo demostró adolecer de serias contradicciones internas que, junto con el deterioro del contexto externo, implicaron la ruptura del equilibrio social preexistente e incluso comprometieron la sustentabilidad del equilibrio económico alcanzado (Bonvecchi y Porta, 2003). El siglo XX culminó con una recesión que alcanzó su punto más álgido en 2001/2002, constituyendo una crisis institucional y económica de gran magnitud. A partir de 2003 la economía comenzó a recuperarse, alcanzando niveles de actividad superiores a los de inicios de los noventa. El crecimiento del producto, el fortalecimiento de las instituciones laborales, y la mayor protección social que brindó el Estado contribuyeron a su vez a mejorar los indicadores sociales. Estas tendencias se resumen en el Cuadro 1. 
REVISTA LATINOAMERICANA DE ESTUDIOS EDUCATIVOS, VOL. XLVI, NÚM. 2, 2016

CUADRO 1: Indicadores de contexto socioeconómico, 1992-2012

\begin{tabular}{|c|c|c|c|c|}
\hline Año & PBI & Tasa de desempleo ${ }^{* *}(\%)$ & Coeficiente de Gini* & Incidencia de la pobreza •* (\%) \\
\hline 1992 & - & 6.8 & 0.450 & 12.7 \\
\hline 1994 & 250.308 & 12.3 & 0.453 & 17.0 \\
\hline 1996 & 256.626 & 17.7 & 0.486 & 22.6 \\
\hline 1998 & 288.123 & 12.8 & 0.502 & 21.4 \\
\hline 2000 & 276.173 & 14.8 & 0.504 & 27.5 \\
\hline 2002 & 235.236 & 17.9 & 0.533 & 45.5 \\
\hline 2004 & 279.141 & 15.1 & 0.507 & 34.7 \\
\hline 2006 & 330.565 & 11.1 & 0.479 & 23.9 \\
\hline 2008 & 383.444 & 8.2 & 0.457 & 17.7 \\
\hline 2010 & 422.130 & 8.0 & 0.443 & 14.8 \\
\hline 2012 & 468.301 & 7.1 & 0.426 & 11.8 \\
\hline
\end{tabular}

Nota: * En millones de pesos, a precios de 1993; **Número de desempleados/población económicamente activa; • Basado en la distribución de los ingresos per cápita familiares; • • Porcentaje de personas cuyos ingresos familiares per cápita no superan la línea de pobreza de 4 dólares diarios. Fuente: INDEC y SEDLAC (CEDLAS y Banco Mundial).

El saldo social del modelo implementado en los noventa resultó altamente desfavorable. El proceso de reconversión transformó profundamente la relación del Estado con la economía y la sociedad, limitando sus posibilidades de actuar como red de contención frente a la vulnerabilidad de ciertos sectores de la población (Veleda, Rivas y Mezzadra, 2011). Asimismo, la desregulación de las relaciones laborales y la mayor fragmentación del sistema productivo debilitaron el mercado de trabajo, rompiendo con la tradición nacional de pleno empleo y protección social.

La crisis del empleo alcanzó una virulencia inusitada durante el régimen de convertibilidad y, si bien en la actualidad la tasa de desempleo total ha vuelto a ubicarse por debajo de $10 \%$, continúa superando los valores de 1992. Asimismo, los problemas de desempleo han ido de la mano de una precarización de la situación de los ocupados, situación que no ha logrado revertirse, aun luego de la recuperación. Según datos de la Socio-Economic Database for Latin America and the Caribbean (SEDLAC), durante todo el periodo bajo estudio, aproximadamente $40 \%$ de los ocupados se ha insertado en el sector de asalariados en firmas pequeñas, cuen- 
tapropistas no profesionales, y trabajadores sin ingresos. Dentro del segmento de los asalariados, la proporción que no cuenta con el derecho a una jubilación era de $35 \%$ en 2012. Asimismo, la brecha salarial entre los sectores formal e informal ha aumentado.

La situación en el mercado laboral ha tenido su correlato en los patrones de desigualdad y pobreza. Durante los noventa se registró un gran crecimiento del coeficiente de Gini, que luego de la crisis comenzó a descender (Cuadro 1). Sin embargo, aún resulta significativa la inequidad en la distribución del ingreso. Además, Veleda, Rivas y Mezzadra (2011) sostienen que las crecientes desigualdades durante estas décadas implicaron una fragmentación del tejido social que llevó a los distintos estratos a frecuentar circuitos de socialización específicos. Así, la segregación residencial cobró una importancia inédita (Cerrutti y Grimson, 2005). Adicionalmente, la pobreza ha profundizado su cronicidad, y si bien la recuperación de los últimos ańos y el rol más activo del Estado han permitido un descenso radical de su incidencia, continúa siendo relevante.

En suma, se registró un retroceso en materia de desarrollo económico que resulta duro de revertir aun después de varios años de recuperación. Es más, algunos de los logros económicos y sociales de esta última fase parecen enfrentar limitaciones, observándose cierta desaceleración en el ritmo de las mejoras. En definitiva, los rasgos cohesivos que poseía tradicionalmente la sociedad argentina se han debilitado, redundando en una estructura social repleta de dualidades, donde abundan los espacios de exclusión. Esto implica un deterioro de las condiciones de educabilidad (López y Tedesco, 2002) en las que muchos jóvenes llegan a las escuelas. Estas tendencias, inevitablemente, han impactado de lleno en las dinámicas desarrolladas al interior del sistema educativo.

\section{El sistema educativo: insumos y reforma institucional}

Durante las últimas dos décadas, en particular, se han sucedido en el país distintas reformas que redefinieron la organización del sistema educativo, su forma de articulación con la sociedad y la provisión de recursos gubernamentales. Las mismas se exponen brevemente a continuación. 


\section{La reforma educativa de los noventa}

En el marco de la reforma general del Estado, la Argentina emprendió a inicios de los noventa una transformación radical de su sistema educativo. El proceso fue global, incluyendo nuevas propuestas organizacionales, administrativas, curriculares y financieras, que alcanzaron a todos los aspectos y niveles del sistema y se aplicaron de forma rápida y simultánea (Minteguiaga Garaban, 2009).

El objetivo manifiesto fue ciertamente ambicioso: mejorar la cobertura, la calidad y la equidad en la educación básica (Becerra, Espańa y Fiszbein, 2003), especialmente en el nivel medio. Sin embargo, diversos autores señalan que existieron otros fines, implícitos, que en algunos casos obstaculizaron estas metas explícitas. Así, reducir el gasto del Estado nacional en educación, aumentar la participación del sector privado, e incrementar la eficiencia y la calidad para promover la competitividad de la economía, serían algunos de estos objetivos alternativos (Zaccagnini, 2002; Minteguiaga Garaban, 2009).

Los instrumentos legales de la reforma fueron los siguientes: i) Ley de Transferencia de Servicios Educativos (1991); ii) Ley Federal de Educación (1993); iii) Pacto Federal Educativo (1994); y iv) Ley de Educación Superior (1995).

Mediante la Ley de Transferencia se concluyó el proceso de descentralización iniciado a fines de los setenta, trasladando la responsabilidad de la educación secundaria y superior no universitaria a las provincias y al Gobierno de la Ciudad de Buenos Aires.

La nueva ley marco para el sistema educativo fue la Ley Federal de Educación (LFE) que: extendió la obligatoriedad de siete a diez años de estudio; modificó los diseńos curriculares y redefinió las responsabilidades de las instituciones; incluyó claramente a la educación privada dentro del esquema público; estableció la creación de un sistema nacional de información y evaluación educativa, y definió un plan de capacitación docente.

La aplicación de la LFE implicó la necesidad de captar recursos públicos adicionales, lo cual fue contemplado en la meta de duplicación gradual del gasto total en educación sobre el nivel de 1992. El Estado nacional se comprometió a financiar programas compensatorios para mitigar desequilibrios provinciales y solucionar emergencias. 
El Pacto Federal Educativo fue firmado entre el Gobierno Federal y cada una de las provincias con la finalidad de asegurar un esfuerzo conjunto de aumento de la inversión pública en educación. Finalmente, la Ley de Educación Superior consolidó un nuevo marco normativo para el desarrollo de este nivel.

Conforme a la responsabilidad asumida por ley, el Ministerio Nacional implementó distintos planes compensatorios o de discriminación positiva que, según Reimers (2000) y Veleda, Rivas y Mezzadra (2011), buscaron focalizar los esfuerzos en la población más desfavorecida, respondiendo a una nueva noción de equidad que se imponía a la de igualdad. Así, en 1993 se creó el Plan Social Educativo, orientado a mitigar las desigualdades regionales en materia de infraestructura, recursos pedagógicos y humanos, y a fomentar la demanda de nivel medio a través del otorgamiento de becas.

Entre los elementos de la reforma, tres resultan aquí de particular interés por su impacto en la equidad educativa: el proceso de descentralización a las provincias, la evolución del financiamiento, y la creciente participación del sector privado.

La descentralización educativa se justificó, de acuerdo con Minteguiaga Garaban (2009), desde un diagnóstico de crisis estructural del sistema y desde una lógica administrativa. Según esta autora, la descentralización involucró dos líneas principales: una ligada a la autonomía escolar, y otra ligada a la federalización, siendo esta última la más relevante. A su vez, se ha sostenido que la intención principal fue la de reducir el gasto del gobierno nacional, ya que la transferencia de responsabilidades no fue acompañada por un traspaso de recursos adicionales (Morduchowicz, 2010).

A pesar de cierto apoyo por parte del gobierno central, la descentralización ha contribuido a profundizar las brechas regionales en la oferta educativa. Esto se debe tanto a la existencia de desigualdades en el gasto destinado a la educación en cada provincia, como a la capacidad fiscal dispar entre las jurisdicciones (Morduchowicz, 2010; Rivas, Vera y Bezem, 2010), a lo cual se suman las diferencias en la gobernabilidad y calidad institucional. Estas dificultades se vieron exacerbadas por la velocidad que adoptó el proceso de transferencias, en el marco de una reforma más amplia que expandió los requerimientos del sistema (Bordón, 2010). Así, 
diversos estudios como el de Veleda, Rivas, y Mezzadra (2011) o Rivas, Vera, y Bezem (2010) dan cuenta de grandes brechas interprovinciales en materia de inversión total, gasto por alumno y salarios docentes.

En lo que respecta al financiamiento a nivel global, puede afirmarse que la implementación de la reforma fue acompańada por un crecimiento prácticamente ininterrumpido del gasto público real en educación. Según la Dirección de Análisis de Gasto Público y Programas Sociales, luego de una caída durante la década de los ochenta, el Gasto Público Consolidado en Educación, Cultura, Ciencia y Técnica creció en términos reales en forma sostenida entre 1990 y 2001. Esta tendencia se vio alterada solo durante los momentos de recesión, coincidiendo la recuperación del gasto con las etapas de crecimiento económico. El gasto público en educación básica siguió un sendero paralelo. Esto implicó a su vez un crecimiento continuo en el gasto público en educación en relación con el PBI, que trepó de $4.1 \%$ a $5.2 \%$ entre 1996 y 2001.

Entonces, durante los años iniciales de la reforma el incremento de la demanda fue compensado con mayores recursos, destinados a ampliar el número de cargos docentes, a programas de capacitación, a inversiones de capital, y a acciones compensatorias (Becerra, España y Fiszbein, 2003). Sin embargo, el carácter pro-cíclico del gasto determinó una disminución del impulso transformador durante la crisis de fines del siglo XX. En este momento también se modificó el esquema de prioridades, ya que a partir de 2002 el gobierno comenzó a re-direccionar recursos, profundizando su apoyo asistencial a través del sistema educativo. Autores como Becerra, España y Fiszbein (op. cit.) sostienen que buena parte del presupuesto nacional comenzó a orientarse a otros componentes, sacrificando partidas destinadas a atender a la eficiencia interna y la calidad. Asimismo, Morduchowicz (2010) argumenta que continúan vigentes algunas dificultades relacionadas con el financiamiento, que se verifican desde hace más de cuarenta ańos: la inorganicidad, la inestabilidad, el incumplimiento y la insuficiencia.

El último elemento que se desea destacar del proceso de reforma es que parece haber favorecido el aumento de la participación 
del sector privado en la provisión de educación básica, proceso que ya llevaba varias décadas. Complementando la presión de demanda durante esta época, en un marco de desprestigio del sector público como prestador de servicios, la progresiva desregulación de los centros privados y la concesión de un estatus legal análogo al de las escuelas estatales contribuyeron a la privatización de la matrícula. Este proceso se analiza en Krüger (2014), dónde se muestra cómo ha reforzado la segregación de los alumnos por NSE entre ambos sectores de gestión, situación que tiende a profundizar la desigualad en los logros educativos.

En general, las críticas hacia la reforma de los noventa se enfocaron en los objetivos implícitos de disminución del gasto educativo a nivel central; en los cambios curriculares y en la estructura académica (Ruiz, 2009); o en la falta de identificación de los actores con los fundamentos de la reforma, que siguió un esquema "de arriba hacia abajo" (Zaccagnini, 2002; Gallegos, 2005). Además, fundamentalmente, subrayaron los mencionados problemas relativos a la descentralización y el financiamiento.

\section{La reforma educativa de principios del siglo XXI}

A partir de 2005 ha comenzado a gestarse un nuevo proceso de reforma educativa en Argentina a través de una legislación que intenta superar algunas de las dificultades ostensibles del sistema educativo nacional (Bordón, 2010). Se trata de dos leyes que regulan aspectos parciales de la educación -Ley 26.058 de Educación Técnico Profesional y Ley 26.075 de Financiamiento Educativo, sancionadas en 2005 y una ley orgánica -Ley 26.206 de Educación Nacional-, sancionada en 2006.

La Ley de Financiamiento apunta a incrementar la inversión en Educación, Ciencia y Tecnología por parte del Estado nacional y de las provincias, aumentándola año a año (en ese momento 4\% del PBI) hasta llegar en el 2010 al 6\% del PBI. Además, especifica cuánto debe aportar cada uno de los niveles de gobierno, y cómo deben distribuirse los recursos hacia las provincias (Morduchowicz, 2010). Si bien el esfuerzo principal recae nuevamente sobre las provincias, el Estado nacional debe incrementar su contribución al gasto educativo. Según el informe 
del Centro de Implementación de Políticas Públicas para la Equidad y el Crecimiento (CIPPEC, 2011), en términos generales las distintas jurisdicciones han sostenido sus compromisos, lo cual ha permitido una recomposición de los salarios docentes luego de su aplicación. Sin embargo, los autores advierten que la nueva ley no ha logrado modificar la gran desigualdad en el gasto educativo y los salarios entre provincias, que incluso ha crecido levemente durante los últimos años.

La Ley de Educación Nacional, por su parte, fija los nuevos objetivos de la política educativa. Entre ellos, se evidencia la meta de alcanzar un mayor grado de coherencia e integración a nivel de todo el país y un mayor nivel de equidad; se extiende la obligatoriedad a todo el nivel secundario, y se modifica la estructura académica.

A su vez, durante este periodo se continuó con la implementación de políticas socioeducativas de carácter focalizado y compensador, creándose importantes programas nacionales para sostener la oferta y la demanda de educación básica.

En suma, como aspectos positivos de la nueva reforma pueden mencionarse la creciente inversión en educación y los mayores esfuerzos por subsanar las desigualdades interprovinciales y socioeducativas. Sin embargo, es posible señalar algunas debilidades de la nueva etapa iniciada. Por un lado, es cuestionable la implementación de una profunda reforma en un plazo relativamente corto y sin mediar un diagnóstico integral (Ruiz, 2009). Por otro lado, preocupan las dificultades que algunas provincias han presentado para cumplir con los objetivos de financiamiento y las persistentes disparidades regionales.

\section{La equidad educativa interna}

Luego del análisis anterior, surgen los interrogantes siguientes: ¿Cómo han repercutido estos cambios en el desempeño del sistema educativo? ¿Cuáles fueron los resultados del esfuerzo realizado a través de la reforma educativa? ¿Ha prevalecido el efecto de las turbulencias en el escenario social?

En esta sección se analizan distintos indicadores para evaluar cómo los cambios en la demanda y oferta de educación han im- 
pactado en la eficiencia interna del sistema. El análisis se focaliza en la educación básica y en dos de los ejes de inequidad más relevantes: el origen socioeconómico y las brechas interprovinciales.

\section{La evolución del acceso al sistema educativo}

En principio, se observa que durante el periodo se ha prolongado la continua expansión experimentada por el sector durante el siglo pasado (Cuadro 2). Detrás de los crecientes niveles de demanda y de oferta se adivinan nociones coherentes con las teorías funcionalistas, que otorgan un valor central a la educación en los procesos de movilidad social ascendente y de desarrollo socioeconómico.

CUADR0 2. Tasas de escolarización específicas, 1992-2012.

Promedio y brecha entre quintiles de ingresos 1 y 5 , por grupos de edad

\begin{tabular}{|c|c|c|c|c|c|c|}
\hline \multirow{2}{*}{ Año } & \multicolumn{2}{|c|}{3 a 5 años de edad } & \multicolumn{2}{c|}{6 a 12 años deedad } & \multicolumn{2}{c|}{13 a 17 años de edad } \\
\cline { 2 - 7 } & Promedio & Brecha Q5/Q1 & Promedio & Brecha Q5/Q1 & Promedio & Brecha Q5/Q1 \\
\hline 1992 & 34.3 & 2.26 & 98.0 & 1.01 & 78.4 & 1.32 \\
\hline 1994 & 30.0 & 1.60 & 98.4 & 1.03 & 79.9 & 1.32 \\
\hline 1996 & 33.8 & 1.94 & 98.9 & 1.02 & 79.3 & 1.51 \\
\hline 1998 & 42.0 & 1.87 & 99.1 & 1.02 & 86.9 & 1.26 \\
\hline 2000 & 43.0 & 1.91 & 99.2 & 1.02 & 90.3 & 1.16 \\
\hline 2002 & 41.8 & 2.04 & 99.3 & 1.01 & 91.5 & 1.17 \\
\hline 2004 & 63.1 & 1.37 & 99.0 & 1.00 & 91.1 & 1.16 \\
\hline 2006 & 66.1 & 1.52 & 99.4 & 1.01 & 91.9 & 1.13 \\
\hline 2008 & 70.2 & 1.31 & 99.1 & 1.01 & 91.2 & 1.11 \\
\hline 2010 & 72.9 & 1.29 & 99.3 & 1.00 & 92.6 & 1.11 \\
\hline 2012 & 72.3 & 1.26 & 98.8 & 1.00 & 91.3 & 1.09 \\
\hline
\end{tabular}

Fuente. SEDLAC (CEDLAS y Banco Mundial)

Desde 1993 la educación es obligatoria en el país a partir de los 5 años de edad ${ }^{3} \mathrm{y}$, como ha ocurrido en gran parte de América

\footnotetext{
${ }^{3}$ La Ley 27.045, promulgada en enero de 2015, amplió la obligatoriedad a partir de los 4 años.
} 
Latina, el creciente consenso político y académico en torno a la importancia de la educación en la primera infancia se ha reflejado en una mejora de las condiciones de oferta en el nivel inicial (Gamboa y Krüger, 2014). Sumado al interés por parte de la demanda, esto se ha traducido en una asistencia cada vez mayor en el grupo etario de 3 a 5 ańos, y en una apreciable reducción de las brechas de acceso por nivel de ingresos familiares.

Por otra parte, mientras que la cobertura en el nivel primario era prácticamente universal ya a principios de la década de los noventa, aún quedaba un porcentaje relevante de jóvenes en edad de asistir al secundario que no se encontraba escolarizado. Con la implantación de la reforma educativa a partir de 1996 y hasta 2002 se observa un salto en la asistencia de los jóvenes, que luego oscila en torno a $91 \%$.

Esta más reciente desaceleración puede explicarse de diversas maneras. Por un lado, podría reflejar que la población que resta incorporar al sistema es la que presenta mayores dificultades de acceso (Tedesco y López, 2002). De hecho, en 2012 aún faltaba integrar a $12 \%$ de los jóvenes pertenecientes al primer quintil de ingresos, proporción muy similar a la de principios de siglo. Por otro lado, Rivas, Vera y Bezem (2010) enfatizan que, en el contexto de recuperación de la economía, el costo de oportunidad de la escolarización para los jóvenes creció, propiciando su sustitución por una inserción laboral temprana.

Además, los niveles promedio esconden disparidades entre grupos de la población. Por ejemplo, los datos del Sistema de Información de Tendencias Educativas en América Latina (SITEAL) permiten desagregar la tasa de escolarización en función del nivel educativo del hogar. Así, entre los jóvenes de 15 a 17 años de edad, solo 46\% de quienes provenían de un hogar con clima educativo bajo -menos de 6 años de estudio en promedio entre los adultos asistía al colegio en 1993, mientras que 93\% de quienes tenían un clima educativo alto -12 años o más- lo hacía. Para 2013, estas tasas eran de 65 y 97\%, respectivamente. Entonces, si bien se evidencia un creciente acceso por parte de los adolescentes desfavorecidos, las brechas continúan siendo significativas.

Otro reflejo de la inequidad es la dispersión de los indicadores entre las jurisdicciones, como se aprecia a través de la Gráfica 1. 
Se observa que al tiempo que Tierra del Fuego y la Ciudad Autónoma de Buenos Aires (C.A.B.A.) presentan tasas de escolarización para los jóvenes superiores a $90 \%$, provincias más pobres como Misiones y Santiago del Estero registran tasas cercanas a 70\%.

GRÁFICA 1. Tasas de asistencia según jurisdicción, 2010

Población de 15 a 17 años

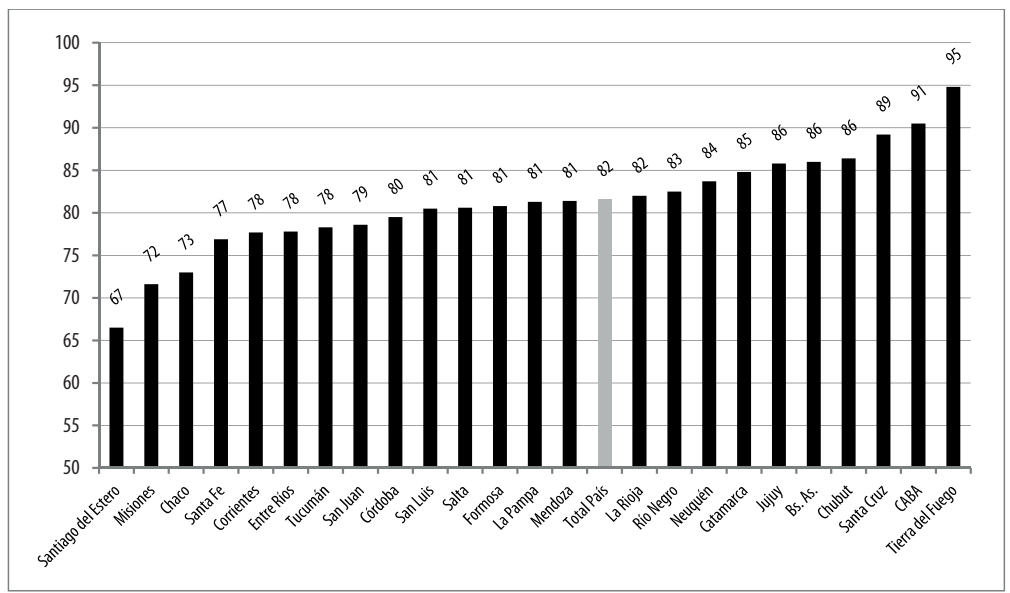

Fuente. Elaboración propia en base al Censo Nacional de Población, Hogares y Vivienda. Año 2010. INDEC.

Recapitulando, pese a las restricciones socioeconómicas, durante las últimas décadas se registraron importantes avances en términos de la cobertura en educación básica. No puede ignorarse, sin embargo, que la masificación se ha dado en forma diferenciada. Continúan siendo relevantes el capital socioeconómico del hogar y el lugar de residencia como determinantes del acceso. En definitiva, si bien se ha logrado incorporar a sectores sociales históricamente excluidos, las barreras estructurales aún no han sido superadas.

Más aún, puede considerarse que la expansión del acceso en el marco de una creciente fragmentación social ha contribuido a afianzar los mecanismos de reproducción de las desigualdades al interior del sistema educativo. Estos desafíos han sido más relevantes en el nivel medio, por ser el que tuvo que adaptarse no solo al deterioro del contexto social sino también a la inédita y progre- 
siva inclusión de los sectores populares (Veleda, Rivas, y Mezzadra, 2011). La conjunción de diversos factores ha obstaculizado la respuesta del sector ante las crecientes exigencias: la velocidad de la expansión de la matrícula; las dificultades planteadas por la descentralización; la desatención de los salarios y condiciones laborales de los docentes, y el creciente rol asistencialista cumplido por la escuela, que obligó a relegar cuestiones vinculadas con la enseñanza-aprendizaje.

Dos son los dilemas ligados a la masificación que se desea destacar aquí: i) el declive de la calidad y la eficiencia interna del sistema, que relativiza la expansión cuantitativa; y ii) la profundización de la segmentación educativa, es decir, la existencia de circuitos de calidad diferenciada que atienden a distintos perfiles de alumnos.

\section{La evolución de los resultados internos del sistema educativo}

Comprobado el creciente acceso a la educación común durante el periodo, cabe preguntarse qué implica el mismo en términos de conocimientos y aprendizaje por parte de los nuevos alumnos. En este sentido, "Existe consenso en que el aumento de la matrícula ha contribuido a deteriorar aún más la calidad de la educación que reciben estos estudiantes" (Filmus et al., 2001: 102).

Pero, ¿qué se entiende por calidad educativa? Este es un concepto muy complejo, y en la literatura pueden encontrarse distintas definiciones. Entre las que resumen Wolff y De Moura Castro (2000), aquí se toma a la "calidad del resultado", que tiene en cuenta el grado en que los estudiantes obtienen los saberes o habilidades que la sociedad desea inculcarles. Los resultados pueden medirse desde distintos ángulos, escogiéndose aquí a los relacionados con el rendimiento, la progresión y la conclusión de los distintos niveles.

\section{La progresión y la terminalidad}

En principio, es clara la dificultad de los alumnos argentinos para permanecer en el nivel educativo correspondiente a su edad. Esto responde a razones diversas como la repitencia, el ausentismo 
prolongado, la deserción temporaria o el ingreso tardío. El rezago etario queda reflejado en la tasa de extraedad, que según los Relevamientos Anuales implementados por la Dirección Nacional de Información y Evaluación de la Calidad Educativa (DiNIECE), apenas ha descendido desde fines de los noventa hasta la actualidad. En 2013 tomaba valores significativos: 36\% en el nivel secundario y $16 \%$ en el primario.

La repitencia, por su parte, ha crecido entre 1997 y 2012 en el caso del nivel medio, y disminuido en la educación primaria. Según los últimos datos disponibles, resulta más relevante en el Ciclo Básico del secundario: 11.4\% de los alumnos se matricula como repitente al año siguiente. En el Ciclo Orientado, en cambio, la tasa asciende a $6.2 \%$, y en el nivel primario a $2.9 \%$.

El rezago puede a su vez incidir en la deserción, por su impacto sobre las expectativas, la confianza y la autoestima del alumno. La evidencia para el periodo, aportada por la DiNIECE, es poco auspiciosa: las tasas de abandono interanual se han mantenido relativamente estables, profundizándose el problema a partir de la crisis de fin de siglo. En 2012, si bien en la escuela primaria los valores eran muy bajos (menores a 1\%), en el nivel medio el problema se concentraba, aproximándose a $9 \%$ durante los primeros años y a $15 \%$ en el Ciclo Superior. Es decir, el fenómeno se va agravando a medida que los alumnos avanzan en sus trayectorias educativas, ya que a la acumulación de problemas de aprendizaje se suma el crecimiento del costo de oportunidad del estudio.

Como consecuencia, la terminalidad no ha mejorado sustancialmente. De hecho, según datos de la DiNIECE, la tasa de egreso en el 1er ciclo del secundario bajó de $74 \%$ en 2001 a $70 \%$ en 2011. En 2 do ciclo, no ha alcanzado $60 \%$ desde los noventa.

Por otra parte, si bien la evidencia disponible es escasa, permite identificar posibilidades diferenciales de progresión y conclusión para los distintos grupos. Por ejemplo, la información recabada por el SITEAL demuestra que en el problema del rezago escolar tiene un rol clave el NSE de los hogares. Quienes provienen de familias con un mayor clima educativo o un alto nivel de ingresos se encuentran en clara ventaja frente a los demás segmentos, y estas brechas -que son del orden de 10 a $20 \%$ - no se han reducido sustancialmente desde fines de los noventa hasta la actualidad. 
A su vez, según la ronda 2014 de la Encuesta Permanente de Hogares (EPH) el NSE es un determinante clave para la conclusión de la educación primaria y secundaria. Mientras que $95 \%$ de los jóvenes de 15 a 19 años pertenecientes al quintil 1 de ingresos per cápita familiares completaba el primario, 98\% del quintil 5 lo hacía. Para el ciclo secundario y los jóvenes de 19 a 24 años, la brecha se amplía significativamente: la conclusión era de $45 \%$ para los más pobres y de $87 \%$ para los más favorecidos.

Respecto a las brechas interprovinciales, cabe señalar que según los Relevamientos Anuales de la DiNIECE, la disparidad por regiones en indicadores como el abandono, la extraedad o la repitencia en el nivel medio es ostensible. Sin embargo, estas diferencias no se correlacionan necesariamente con la pobreza provincial sino que, tal como aseguran Rivas, Vera y Bezem (2010), podrían vincularse a factores como los modelos curriculares o institucionales, que luego de la descentralización han evolucionado de manera diferente.

Ahora bien, más allá de las deficiencias señaladas, es evidente que el creciente acceso al sistema educativo durante las últimas décadas ha redundado en una mejor estructura de cualificaciones para la población argentina. Los datos proporcionados por SITEAL indican que ha crecido significativamente el porcentaje de la población de más de 20 años de edad que logró completar el nivel secundario (de 17 a $24 \%$ entre 1993 y 2013) y el porcentaje de la población mayor de 25 años de edad que logró completar el nivel terciario (de 12 a 20\% entre 1998 y 2013). Así, ha mejorado sustancialmente la distribución de la educación: el Coeficiente de Gini para los ańos de estudio tomaba un valor de 0.231 a principios de los noventa, se había reducido a 0.227 para 2001 y a 0.196 para 2012 (SEDLAC).

No obstante, cabe destacar la proporción de la población de 19 a 24 años de edad que en 2014 no había logrado completar el nivel secundario: $37.5 \%$ según los datos provistos por la EPH. Además, en este grupo se encontraban sobrerrepresentados los segmentos de menor NSE.

$\mathrm{Al}$ analizar nuevamente la geografía provincial de los logros educativos, se observan deudas pendientes. Para 2009, aún persistían importantes disparidades en la estructura educativa de los 
distintos aglomerados (Gráfica 2). Mientras que más de $80 \%$ de la población adulta de la C.A.B.A. había terminado como mínimo el nivel secundario, en el Conurbano Bonaerense o en el Nordeste argentino este porcentaje era cercano a 50\%. A su vez, el Índice de Gini de los años de educación indica que existían grados diversos de inequidad en su distribución. Esto demuestra que aún perduran desigualdades históricas que las sucesivas reformas no han logrado reparar.

GRÁFICA 2. Estructura educativa (2009) y Coeficiente de Gini de los años de educación (2010) por jurisdicciones. Población de 25 a 59 años de edad

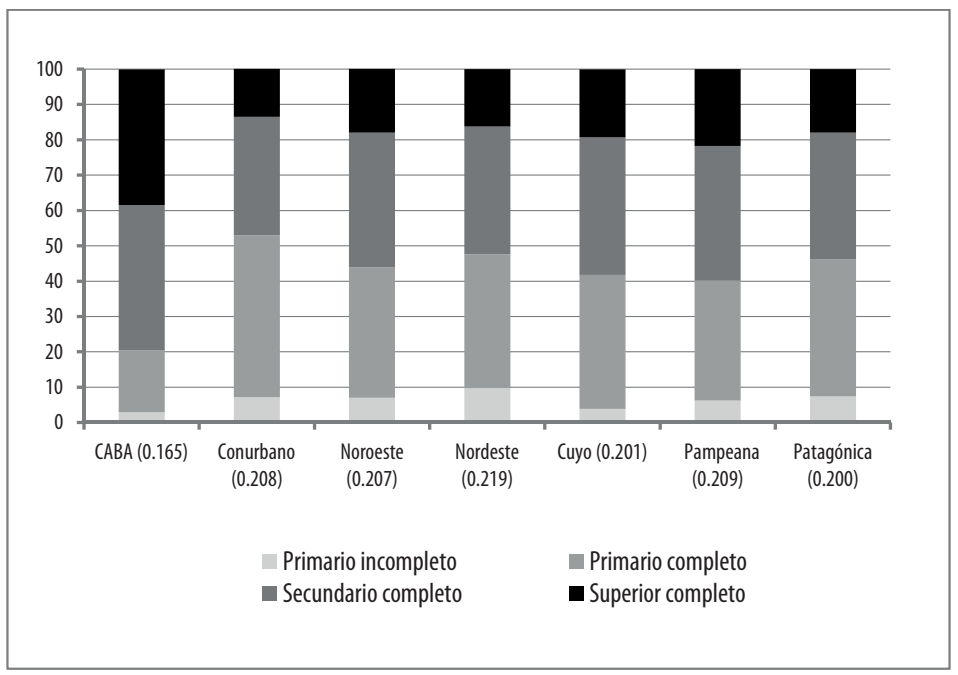

Nota. El Coeficiente de Gini se presenta entre paréntesis debajo del nombre de cada región. Fuente. Elaboración propia a partir de DiNIECE (2010a); y Casal, Morales y Paz Terán (2011).

\section{La calidad de los aprendizajes}

Esto se relaciona con el grado de exposición cuantitativa y cualitativa a los aprendizajes al interior del aula, y con los conocimientos y competencias adquiridos. Por ello, una cuestión de relevancia 
es el tiempo de enseñanza. Si bien medirlo es complejo, existen algunos indicadores básicos como las horas de instrucción teóricas, o la extensión de la jornada escolar. Tenti Fanfani, Meo, y Gunturiz (2010) recopilan información de diversas fuentes para afirmar que los países de América Latina presentan en promedio un número de horas de enseñanza oficial relativamente bajo. Asimismo, se señala que Argentina se ubica entre los puestos más bajos en la región respecto a este indicador.

A su vez, más allá del escaso tiempo escolar oficial en el país, preocupa el hecho de que el tiempo de enseñanza efectivo suele ser muy variable. Frecuentemente se pierden días enteros de clase debido al ausentismo docente, las huelgas gremiales, o los problemas edilicios. Asimismo, existe al respecto una gran disparidad interprovincial por la disimilitud en los contextos políticos y el grado de conflictividad (Rivas, Vera y Bezem, 2010). Esta situación resulta perjudicial no solo por la disminución en el tiempo total de enseñanza, sino por el impacto proveniente de la interrupción del ciclo lectivo.

Durante la última década, la preocupación en torno a la extensión del tiempo escolar ha sido central en la política educativa nacional (Tenti Fanfani, Meo, y Gunturiz, 2010). Por ejemplo, la Ley 24.864 estableció un ciclo lectivo anual mínimo de 180 días de clase para todo el país en la Educación Básica. Luego, la Ley de Financiamiento Educativo de 2005 fijó la meta de brindar una oferta de escuelas de jornada extendida o completa a 30\% de los alumnos de primaria y secundaria. Sin embargo, la evidencia disponible indica que esta oferta es muy limitada, se encuentra concentrada en el nivel primario y en el sector privado, y resulta muy heterogénea entre jurisdicciones (Veleda, 2013).

Por otra parte, desde hace décadas se ha visto a nivel internacional una creciente preocupación por la medición de la calidad educativa desde el punto de vista de los conocimientos o las competencias adquiridas, desarrollándose numerosas evaluaciones desde diversos ámbitos. Si bien, como afirman Rivas, Vera, y Bezem (2010), los resultados de estas pruebas deben interpretarse con cautela, la información que proveen es muy rica, y refleja a grandes rasgos la evolución y la distribución de los aprendizajes. 
Una de las pruebas internacionales más reconocidas es la elaborada por la Organización para la Cooperación y el Desarrollo Económicos (OCDE), conocida como el Programa para la Evaluación Internacional de Alumnos (PISA, por sus siglas en inglés). Este estudio tiene como objetivo evaluar la capacidad de los jóvenes de 15 ańos para emplear su conocimiento y habilidades frente a los desafíos de la sociedad actual. Se realiza cada tres años desde 2000 y consiste de una serie de evaluaciones de las competencias de los estudiantes en matemática, ciencias y lectura. A su vez, provee información acerca del contexto familiar de los alumnos y de las características de los centros.

La Argentina ha participado de las rondas 2000, 2006, 2009 y 2012, y en general ha presentado resultados precarios en términos de la performance global y la igualdad. Resulta preocupante el hecho de que los puntajes promedio no han mejorado entre los extremos del periodo: han pasado de 418 a 396 en lectura, de 396 a 406 en ciencias, y se han mantenido en 388 en matemática (OCDE, 2003 y 2013). Asimismo, el porcentaje de alumnos con un logro por debajo del Nivel 2 de competencias -el mínimo necesario para participar activamente en la sociedad, según OCDE (2010) - era de 66\% para matemáticas en 2012, mucho mayor a $23 \%$ para el promedio de los países de la OCDE.

Respecto al grado de desigualdad en los resultados, si bien se logró una disminución entre la primera y última ronda del estudio (Rivas, 2015), aún resulta relevante la incidencia del NSE de origen. A modo de ejemplo, se puede comparar los puntajes medios alcanzados por los alumnos pertenecientes a cada cuartil del índice de Estatus Económico Social y Cultural (ESCS) de los hogares: estos eran, para matemáticas, 355, 379, 394 y 433 del primero al cuarto, respectivamente.

En el ámbito nacional, se implementa anualmente una prueba de evaluación de la calidad educativa desde 1993, por disposición de la LFE. Se trata del Operativo Nacional de Evaluación (ONE), planificado, coordinado y aplicado por la DiNIECE. Durante estos relevamientos se aplican pruebas de conocimientos en las áreas de matemática, lengua, ciencias sociales y ciencias naturales a los alumnos matriculados en distintos tramos del primario y del secundario a lo largo de todo el país. 
Lamentablemente, las deficiencias de las que adolece el estudio-como los cambios metodológicos en el tiempo, la restricción en el acceso a las bases de micro-datos, y la falta de mecanismos de empalme que permitan evaluar la evolución de los resultados entre las sucesivas pruebas- limitan su utilidad.

Ahora bien, en el último operativo llevado a cabo en 2013, el Informe elaborado por la DiNIECE comunica que 28\% de los alumnos del último año de la secundaria obtuvo resultados bajos en matemática, $60 \%$ resultados intermedios -que se corresponderían con un rendimiento satisfactorio- y $12 \%$ resultados altos. En lengua y ciencias sociales el panorama es algo más equitativo, y en ciencias naturales un poco más heterogéneo. A su vez, nuevamente se encuentra una asociación entre el capital socioeconómico de las familias y la performance en los tests (Gráfica 3). Por ejemplo, quienes provienen de un hogar ubicado en el estrato de NSE bajo, alcanzan con una probabilidad de $15 \%$ un resultado alto en matemática, y con una probabilidad de $46 \%$ un resultado bajo. Estas probabilidades se invierten a medida que aumenta el NSE familiar.

GRÁFICA 3. Alumnos (\%) según nivel de desempeño en matemática, ONE 2013

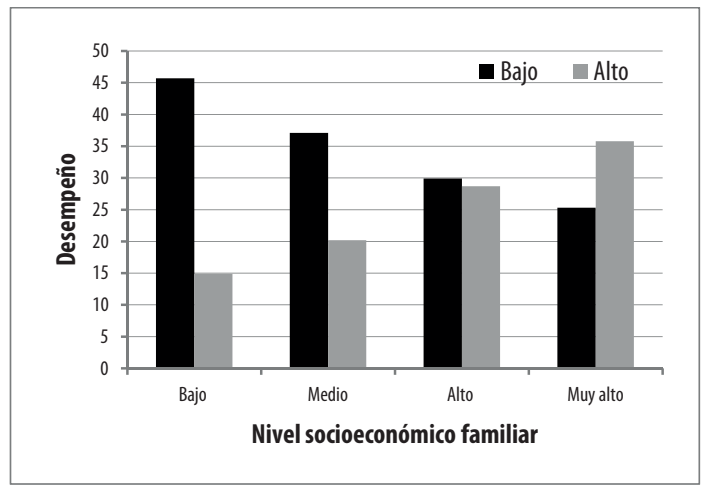




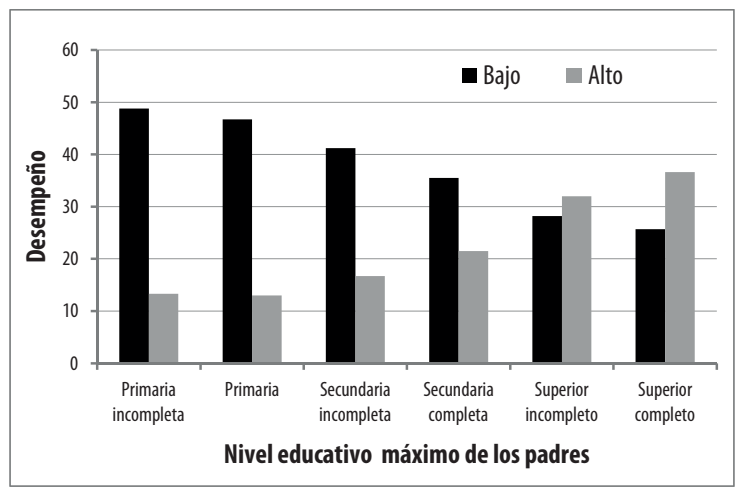

Nota: alumnos de 6 to año de primaria. Fuente: Informe de Resultados ONE 2013. DiNIECE.

Finalmente, se confirma que, al igual que para otros indicadores de eficiencia interna, existen amplias disparidades interregionales en el rendimiento (Cuadro 3). En las provincias más pobres del Noreste y Noroeste, más de 35\% de los alumnos del último año del secundario obtuvo resultados bajos en matemática, y menos de 7\% resultados altos; en la región del Centro o en la Patagonia, la situación es bastante más favorable.

CUADR0 3. Alumnos (\%) según nivel de desempeño en matemática ONE 2013 por jurisdicciones

\begin{tabular}{|l|c|c|c|}
\hline \multirow{2}{*}{ Región } & \multicolumn{3}{|c|}{ Nivel de desempeño } \\
\cline { 2 - 4 } & Bajo & Medio & Alto \\
\hline Región Centro & 23.9 & 61.1 & 15.0 \\
\hline Región NEA & 43.3 & 53.8 & 2.9 \\
\hline Región NOA & 35.5 & 58.0 & 6.5 \\
\hline Región Cuyo & 27.8 & 62.0 & 10.2 \\
\hline Región Patagónica & 23.8 & 63.7 & 12.5 \\
\hline
\end{tabular}

En suma, la evidencia proveniente de distintas fuentes corrobora la percepción generalizada acerca de que los logros en materia de cobertura registrados durante las últimas décadas no 
han sido acompañados por niveles crecientes de calidad global. Además, son los habitantes de las provincias más pobres del país y los sectores marginales quienes más ven vulnerado su derecho a una educación de calidad.

\section{La segmentación educativa}

En relación con esta última conclusión, y tal como se mencionó anteriormente, el segundo de los problemas que parecen haberse agravado recientemente es la incapacidad del sistema educativo para proveer las mismas condiciones de escolarización a todos los grupos sociales. Esta situación de segmentación educativa comprende dos procesos vinculados: la segregación social, o distribución desigual de los alumnos entre centros según su NSE de pertenencia, y la asociación positiva entre los recursos escolares y el estatus social promedio de los alumnos (Krüger, 2011).

La diferenciación horizontal de las escuelas es un fenómeno que se registra en todo el mundo y que tiene cierta historia en Argentina, reconocido por la literatura ya en los ańos ochenta (ver, por ejemplo, Braslavsky, 1985). Sin embargo, en el contexto de los grandes cambios que sufrieron la sociedad y la economía argentina desde los noventa, esta tendencia parece haberse profundizado. Las causas son múltiples y complejas, e incluyen cuestiones como la creciente introducción de lógicas de mercado en el sector educativo; el debilitamiento del rol del Estado; las dificultades para sostener la calidad de la escuela pública; o la mayor selectividad por parte de la demanda, entre otras (Krüger, 2012).

De diversas formas, este proceso contribuye a la reproducción e incluso ampliación de las desigualdades de origen a través de la educación. Por un lado, la segregación de los estudiantes impide que el paso por la escuela se convierta en una instancia de integración y distribución de capital social. Por el otro, según la evidencia aportada en Krüger (2013) y la literatura allí sintetizada, los factores escolares -que incluyen a las características del grupo de pares- inciden significativamente en los logros educativos individuales. Así, la segmentación profundiza el efecto del NSE de pertenencia sobre las trayectorias educativas. 


\section{La equidad educativa externa}

Tal como se ha desarrollado previamente, el vínculo entre la educación y el empleo o los ingresos es materia de amplios debates. Las teorías funcionalistas enfatizan el lado de la oferta para sostener una correspondencia entre educación, productividad laboral e ingresos. Cabría esperar a partir de esta perspectiva que la mayor equidad educativa registrada en el país se hubiera traducido en una mayor igualdad de oportunidades económicas.

Sin embargo, en la inclusión económica de la población intervienen otros factores como las características del modelo de desarrollo, las políticas del Estado, y otros elementos de contexto que configuran el desempeño del mercado de trabajo. En definitiva, mayor equidad educativa no implica mayor equidad económica (Carnoy, 2004).

De hecho, en Argentina no se aprecia una asociación marcada entre la distribución de la educación adquirida y la de los ingresos familiares durante las últimas décadas. Según datos de SEDLAC, el Coeficiente de Gini de los ańos de educación ha seguido una evolución diferente al del ingreso per cápita de los hogares. Mientras que la tendencia del primero es descendente y sostenida desde 1980 hasta la actualidad, la desigualdad en ingresos ha crecido hasta los primeros años del presente siglo, para luego decrecer. Asimismo, la distribución de educación resulta más equitativa que la de los ingresos.

Dudando del estrecho vínculo entre la educación y los ingresos, el paradigma crítico-reproductivista aporta conceptos que permiten comprender los límites de la educación como mecanismo de ascenso social y de superación de la pobreza. Por su parte, los enfoques que abordaron las problemáticas asociadas a la demanda laboral conservan en gran medida su vigencia y permiten explicar algunas dinámicas registradas en el país.

La idea central que vincula a estas teorías es que no existe una relación unívoca o universal entre educación e ingresos, porque en la misma inciden distintos factores institucionales e históricos, así como la pirámide educativa de la fuerza laboral y el ciclo económico. Es decir, el valor de los certificados educativos depende del contexto en que se los emplee (Miranda, Otero y Zelarayan, 2005). 
Así, en países industrializados como Gran Bretaña, Francia, Alemania y Japón, la extensión promedio de las carreras educativas ha generado un proceso de "inflación de credenciales" que asegura la continuidad del rol de la educación como reproductora de las desigualdades (Heath y Sullivan, 2011). Según estos autores, a medida que las clases sociales medias y altas perciben que el título del nivel secundario no permite asegurar su posición en la escala social, se desarrollan nuevos modos de competencia educativa y ocupacional. La misma puede continuar por la vía de constantes aumentos en la cantidad de escolarización o por una diferenciación de la calidad al interior de cada nivel.

Para la región latinoamericana, desde la CEPAL se señalaba ya a fines de los noventa que el nivel secundario constituía el nuevo umbral educativo mínimo para escapar de la pobreza (CEPAL, 1997). Actualmente, los datos provistos por SITEAL muestran que solo con 13 años de estudios o más los ocupados argentinos logran reducir significativamente sus oportunidades de pertenecer al segmento que percibe ingresos en el 30\% más bajo. En este sentido, diversos analistas coinciden en que desde los años ochenta se ha gestado un proceso de "devaluación de las credenciales educativas" - se ha incrementado el nivel educativo mínimo para el acceso a un mismo puesto de trabajo- y de "compresión hacia abajo" -los sujetos menos calificados son desplazados por los más educados en la estructura de empleo- (Filmus y Sendón, 2001; Miranda, Otero y Zelarayan, 2005).

Más allá de una necesidad real de mayores calificaciones para gestionar procesos productivos más complejos, es la conjunción de la mejora en el perfil educativo de la población con el deterioro en el mercado laboral durante los años ochenta y noventa lo que ha generado un "efecto fila". A la masificación, a su vez, se le ha sumado la percepción del deterioro en la calidad educativa y la segmentación de las escuelas. Este proceso ha afectado especialmente al certificado del nivel medio, que fue perdiendo su antigua función de selección social (Cervini y Tenti Fanfani, 2005).

Para ofrecer un panorama de cómo se han articulado en el país el sistema educativo y el mercado de trabajo, se evalúan a continuación algunos de los principales indicadores de resultados externos. 
Las estadísticas del SEDLAC permiten observar la evolución de las brechas salariales por nivel educativo desde los años noventa (Cuadro 4). Durante el periodo de contracción del mercado laboral, entre 1992 y 2003, se expandieron las brechas de ingresos entre aquellos con un nivel educativo alto y medio y entre aquellos con un nivel medio y bajo.

\section{CUADRO 4: Evolución de las brechas de salarios horarios por nivel educativo, ${ }^{*}$ 1992-2012}

\begin{tabular}{|c|c|c|c|}
\hline Año & Alto/Medio & Medio/Bajo & Alto/Bajo \\
\hline 1992 & 1.86 & 1.41 & 2.61 \\
\hline 1996 & 1.98 & 1.37 & 2.72 \\
\hline 2000 & 2.01 & 1.45 & 2.90 \\
\hline 2004 & 1.83 & 1.30 & 2.37 \\
\hline 2008 & 1.67 & 1.26 & 2.11 \\
\hline 2012 & 1.52 & 1.27 & 1.93 \\
\hline
\end{tabular}

Nota: * Bajo: menos de 9 años de educación formal; Medio: entre 9 y 13 años de educación formal; Alto: más de 13 años de educación formal. Fuente: SEDLAC (CEDLAS y Banco Mundial).

La mayor desventaja para los trabajadores que no contaban con un nivel terciario completo durante los años de recesión y crisis se refleja también en la participación en los ingresos de fuente laboral (SITEAL, 2006). Entre 1990 y 2003, este indicador disminuyó para todos los niveles educativos con la excepción de "superior completo", y los ocupados con secundaria completa fueron los que más vieron caer su participación.

Con la recuperación económica de principios de este siglo, las brechas de ingresos disminuyeron en todos los casos, registrándose una caída en el premio a la educación secundaria y superior. De todos modos, los ingresos de quienes alcanzaron como máximo el nivel medio aún se acercan más a los de menor nivel educativo que a los de mayor calificación. Los datos del SITEAL confirman la caída en el valor relativo del nivel medio: en 1993, $30 \%$ de los ocupados con 10 a 12 años de estudios percibía ingresos ubicados en el 30\% más alto; para 2013 este porcentaje había caído a $27 \%$. Solo quienes contaban con 13 años o más de educación mejoraron su posición. 
A conclusiones similares se arriba analizando las tasas de retorno para los distintos niveles educativos calculadas por SEDLAC. En 1992, poseer el nivel primario completo permitía ganar en promedio $29 \%$ más que un trabajador de similares características sin este título; haber completado el nivel secundario implicaba un incremento de $45 \%$ en promedio sobre los ingresos de un trabajador con educación primaria; mientras que el diploma terciario permitía acceder a un incremento adicional de 56\%. Para 2013, el certificado secundario solo permitía alcanzar un incremento salarial de $27 \%$ por sobre el primario, mientras que el nivel terciario suponía un aumento adicional de $43.5 \%$.

Este fenómeno de devaluación de las credenciales educativas se relaciona estrechamente con el concepto de sobreeducación, situación en la que los trabajadores realizan una tarea que exige competencias menores a aquellas para las cuales fueron formados. Esto se verificó especialmente durante los ańos noventa y la crisis de fin de siglo: según el trabajo de Pérez (2005), entre 1995 y 2003 se incrementó la sobreeducación para todos los trabajadores, pero quienes más han enfrentado este problema son aquellos que cuentan con secundario completo.

El rendimiento de los distintos diplomas educativos puede evaluarse también a través de su capacidad relativa para evitar caer en el desempleo. Si bien existe una relación negativa entre escolaridad y desocupación, la misma no es lineal: según las estadísticas del SITEAL, la probabilidad de caer en el desempleo para el estrato de población que tiene entre 10 y 12 ańos de estudio se asemeja más a la de los segmentos con menor formación que a la de quienes cuentan con 13 años o más de educación. Entre los jóvenes, Sendón (2005) afirma que la inserción laboral parece estar más determinada por las redes sociales y el capital sociocultural de los alumnos que por el valor formal del diploma. Así, la segmentación del sistema educativo se relaciona estrechamente con el acceso al empleo. Se desarrolla un "doble" proceso de compresión hacia abajo: quienes cuentan con mayor escolarización desplazan a los menos calificados, y dentro de cada nivel educativo, quienes provienen de los segmentos escolares más altos desplazan al resto.

Esta caída en el valor de la educación básica se hace extensiva a la precariedad e informalidad laboral. La segmentación del mercado de trabajo determina que una gran proporción de la 
población ocupada acceda a empleos de menor calidad, entre los que se encuentran sobre-representados los trabajadores de menor escolaridad. El SITEAL define al sector informal como el menos productivo de la economía, que incluye a los trabajadores que se emplean en establecimientos de hasta cinco personas, que trabajan por cuenta propia con una baja remuneración, o que son trabajadores familiares sin remuneración fija. Según la base de datos del sitio, existe una relación inversa entre la probabilidad de insertarse en este sector y el nivel educativo. Durante la recuperación reciente de la economía, solo el grupo de trabajadores con más de 13 ańos de estudio registró una disminución relevante en la informalidad. En 2013, la situación de los trabajadores con estudios medios se asemejaba más a la de aquellos con estudios primarios que a la de los más educados.

Las ventajas de completar al menos el nivel secundario se aprecian aún más al considerar el riesgo de caer en la pobreza en un contexto económico adverso. La información provista por la CEPAL en base a la EPH del INDEC permite observar que desde 1994 hasta el pico de la crisis económica en 2002, la incidencia de la pobreza creció extraordinariamente para todos los segmentos, con la excepción de aquellos con terciaria completa. La población más afectada fue la de menor nivel educativo -quienes tenían hasta secundaria incompleta-. No obstante, los grupos con secundaria completa también vieron incrementadas sensiblemente sus oportunidades de caer en esta condición. Solo quienes contaban con el máximo nivel educativo han atravesado todo el periodo con tasas de pobreza inferiores a $5 \%$.

\section{CONCLUSIONES}

Para resumir, ¿qué ha ocurrido con la equidad educativa interna y externa en Argentina desde principios de los noventa hasta la actualidad?

El sector educativo ha sufrido importantes transformaciones en esta etapa, en el marco de una profunda reestructuración del Estado y de grandes cambios en el contexto socioeconómico. Se ha verificado un proceso de masificación que, si bien resultó selectivo, permitió incorporar a números crecientes de adolescentes al nivel medio. Este proceso, sin embargo, no se ha encontrado 
exento de problemas. Integrar a nuevos segmentos de la población estudiantil, de contextos más desfavorables, constituyó un gran desafío. Las respuestas que ha dado el sistema a estos nuevos dilemas no resultan del todo satisfactorias, ya que persisten los problemas de retención, progresión y terminalidad, que afectan especialmente a los jóvenes en desventaja socioeconómica.

Preocupan a su vez el deterioro general en la calidad de los aprendizajes y la segmentación del sistema educativo, reflejados en trayectorias escolares y post-escolares que dependen fuertemente del nivel socioeconómico de origen. Así, para muchos sectores de la población, el acceso al sistema educativo no es sinónimo de acceso a aprendizajes socialmente significativos.

Entonces, más allá de los progresos en términos de la equidad interna, aún existen deudas pendientes. La masificación en términos cuantitativos ha sido diferenciada en términos cualitativos, lo cual ratifica y ahonda las divisiones sociales, minando la capacidad de la educación para reducir las brechas iniciales.

Por otra parte, la evidencia presentada es coherente con los enfoques críticos a la Teoría del Capital Humano, al poner en relieve que la relación entre educación y empleo se encuentra mediada por las características del mercado de trabajo y por el ciclo económico. Durante las últimas décadas se ha dado un más lento crecimiento de las oportunidades ocupacionales respecto de los logros educativos de la mayoría (Rivero, 2005), tal que la mayor equidad educativa no se ha traducido estrictamente en una mayor equidad socioeconómica.

Se destaca el ostensible proceso de devaluación de las credenciales otorgadas por la educación básica, que han mermado su capacidad de "señalizar" la empleabilidad de los trabajadores. Si bien la educación media se comporta como un prerrequisito para acceder a mayores oportunidades en el futuro, la mayor prima en términos de retribuciones esperadas y probabilidad de mantenerse ocupado resulta de completar la educación superior.

Asimismo, los umbrales para evitar la transmisión intergeneracional de la pobreza se han incrementado. Esto resulta problemático no solo porque los esfuerzos de gran parte de la población por adquirir capital humano no se ven recompensados, sino porque aquellos grupos que no logran adquirir las nuevas creden- 
ciales mínimas obligatorias se encuentran en una situación de creciente vulnerabilidad.

Si bien la intención de este trabajo no es la de realizar propuestas de intervención, se espera que contribuya a la generación de un diagnóstico adecuado de los problemas relevantes. No se desconoce que el empleo de estadísticas implica un recorte que solo provee una aproximación a la realidad. Sin embargo, los indicadores seleccionados permiten contar con un panorama general de lo que ha ocurrido en el país durante las últimas décadas.

Son múltiples y complejos los mecanismos involucrados tanto en la reproducción de la desigualdad social al interior del sistema como en la capacidad de la educación para propiciar la equidad social. Estos factores no solo responden al contexto socioeconómico sino que en gran medida son endógenos al sistema educativo. La evidencia aportada confirma que aún continúan vigentes los procesos educativos que según Reimers (2000: 14) transmiten la desigualdad social: acceso diferencial a los distintos niveles educativos según el contexto de pertenencia; mejores condiciones en las escuelas a las que asisten los alumnos de origen favorecido; segregación social estudiantil; las familias con mayor capital socioeconómico y cultural tienen mejores posibilidades para apoyar la educación de sus hijos. Tal como afirma el autor, todos estos procesos pueden ser influidos por medidas de política adecuadas.

Ahora bien, para ello se requiere de políticas integrales, que contemplen todos los factores educativos, económicos y sociales interrelacionados que vinculan a la educación con su medio. Se ha comprobado que los cambios en el sector educativo, por sí solos, no pueden generar una mayor equidad educativa y social. Además, se afirma con Reimers (op. cit.) que se requiere de medidas que efectivamente apunten a reducir la desigualdad de oportunidades entre los distintos grupos sociales, ya que los esfuerzos por aumentar la calidad global de los sistemas solo perpetúan la reproducción de la inequidad existente. Claro está, que para ello se necesita una gran voluntad política, capaz de enfrentarse a los intereses de los distintos actores que pugnan por mantener el statu quo. 


\section{REFERENCIAS BIBLIOGRÁFICAS}

Anderson, E. "What is the point of equality?", en Ethics, 109, 2, 1999, pp. 287-337.

Arrow, K. "Higher education as a filter", en Journal of Public Economics, 2, 3, 1973, pp. 193-216.

Baker, J.; K. Lynch, S. Cantillon, y J. Walsh. Equality: from theory to action, Nueva York, Palgrave Macmillan, 2004.

Becerra, M.; S. España, y A. Fiszbein. "Enfoques sobre la Eficiencia del Gasto en Educación Básica en la Argentina", Doc. de Trabajo núm. 6/03, Banco Mundial, 2003.

Becker, G. Human capital, Nueva York, National Bureau of Economic Research, 1964.

Bonal, J. Sociología de la Educación. Una aproximación critica a las corrientes contemporáneas, Bs. As., Paidós, 1998.

Bonvecchi, C. y F. Porta. Conformación, Auge y Colapso del Paradigma de los Noventa, Bs. As., CEPAL-ONU, 2003.

Bordón, J. "Historia y política de la descentralización y el gobierno educativo en la Argentina", en Andrade Oliveria et al., Politicas educativas y territorios. Modelos de articulación entre niveles de gobierno, Bs. As., IIPE-Unesco, 2010, pp. 113-130.

Boudon, F. La desigualdad de oportunidades, Barcelona, Laia, 1983. Braslavsky, C. La discriminación educativa en Argentina, Bs. As., FLACSO-Grupo Editor Latinoamericano, 1985.

Calero, J. y X. Bonal. Política educativa y gasto público en educación. Aspectos teóricos y una aplicación al caso español, Barcelona, Pomares-Corredor, 1999.

Carnoy, M. "Mayor acceso, equidad y calidad en la educación de América Latina. ¿Qué lecciones deja para el Proyecto Regional de Educación para América Latina y el Caribe?”, en Revista Prelac, OREALC/UNESCO, 1,0, 2004, pp. 43-63.

CEPAL. La brecha de la equidad, Santiago de Chile, CEPAL, 1997.

Cerrutti, M. y A. Grimson. "Buenos Aires, neoliberalismo y después. Cambios socioeconómicos y respuestas populares”, en Portes, Roberts y Grimson (Eds.), La ciudad latinoamericana, Bs. As., Prometeo, 2005.

Cervini, R. y E. Tenti Fanfani. "Notas sobre la masificación de la escolarización en 6 países de América Latina”, en Debate núm. 1, SITEAL, 2005. Disponible en http://www.siteal.iipe-oei.org 
EQUIDAD EDUCATIVA INTERNA Y EXTERNA: PRINCIPALES TENDENCIAS EN ARGENTINA...

CIPPEC. "Monitoreo de la Ley de Financiamiento Educativo. Cuarto Informe Anual 2010”, 2011. Disponible en http://www.cippec.org/Main.php? categoryId=4\&do=do cumentsShow

Cohen, G. "On the currency of egalitarian justice", en Ethics, 99, 4, 1989, pp. 906-944.

Deferranti, D.; G. Perry; F. Ferreira y M, Walton. Inequality in Latin America and the Caribbean: Breaking with History. Washington, D. C., Banco Mundial, 2004.

Feijoó, M. Argentina. Equidad social y educación en los años 90, Bs. As., IIPE-UNESCO, 2002.

Filmus, D.; A. Miranda, M. Moragues, y C. Kaplan. Cada vez más necesaria, cada vez más insuficiente: la escuela media $y$ mercado de trabajo en épocas de globalización, Bs. As., Santillana, 2001.

Filmus, D. y M. Sendón "A la deriva: trayectorias de los egresados de la escuela media en la transición hacia la inserción laboral", V Congreso Nacional de Estudios del Trabajo. ASET, Bs. As., 2001. Disponible en www.aset.org.ar

Formichella, M. "Análisis del concepto de equidad educativa a la luz del enfoque de las capacidades de Amartya Sen”, en Educación, 35, 1, 2011a, pp. 1-36.

Formichella, M. "Reflexiones sobre el rol de la educación universitaria en el desarrollo", en Revista Latinoamericana de Estudios Educativos, XLI, 1-2, 2011b, pp 210-228.

Gallegos, M. "La educación en Latinoamérica y el Caribe: puntos críticos y utopías", en Revista Latinoamericana de Estudios Educativos, XXXV, 1-2, 2005, pp. 7-34.

Gamboa, L.y N. Krüger. “¿Existen diferencias en América Latina en el aporte de la educación inicial al logro educativo futuro? Un estudio a partir de PISA 2009-2012”, en Actas de la XLIX Reunión Anual de la AAEP, noviembre 2014, Posadas, Argentina.

Hanushek, E. y L. Wößmann. "The role of cognitive skills in economic development", en Journal of Economic Literature, 46, 3, 2008, pp. 607-68.

Haretche, C. "Nueva evidencia sobre equidad educativa en seis países latinoamericanos", en Revista Latinoamericana de Estudios Educativos, XLIII, 4, 2013, pp. 21-54. 
Heath, A. y A. Sullivan. "Introduction: The democratisation of upper secondary education?", en Oxford Review of Education, 37, 2, 2011, pp. 123-138.

Heckman, J., L. Lochner y P. Todd "Earnings functions, rates of return and treatment effects: The Mincer equation and beyond", en Hanushek, E. y Welch, F. (Eds): Handbook of the Economics of Education, Amsterdam, North-Holland, 2006.

Krüger, N. "The segmentation of the argentine education system: evidence from PISA 2009", en Regional and Sectoral Economic Studies, 11, 3, 2011, pp. 41-64.

Krüger, N. "La segmentación educativa argentina: reflexiones desde una perspectiva micro y macro social", en Páginas de Educación, 5, 1, 2012, pp.137-156.

Krüger, N. "Segregación social y desigualdad de logros educativos en Argentina", en Education Policy Analysis Archives, 21, 86, 2013, pp.1-30.

Krüger, N. "Más allá del acceso: segregación social e inequidad en el sistema educativo argentino", en Cuadernos de Economía, 33, 63, 2014, pp. 513-542.

López, N. Equidad educativa y desigualdad social, Bs. As., IIPE-UNESCO, 2006.

López, N. y J. Tedesco. "Las condiciones de educabilidad de los niños y adolescentes de América Latina”, en Documentos del IIPE, 2002.

Mincer, J. "Investment in human capital and personal income distribution", en The Journal of Political Economy, 66, 4, 1958, pp. 281-302.

Minteguiaga Garabán, A. Lo público de la educación pública: la reforma educativa de los noventa en Argentina, México, D. F., Flacso México, 2009.

Miranda, A., A. Otero y J. Zelarayán. "Distribución de la educación y desigualdad en el empleo: los jóvenes en la Argentina contemporánea”, en VII Congreso Nacional de Estudios del Trabajo, Bs. As., ASET, 2005.

Morduchowicz, A. "El federalismo fiscal-educativo argentino", en Andrade Oliveria et al., Politicas educativas y territorios modelos de articulación entre niveles de gobierno, Bs. As., IIPE-UNESCO, 2010, pp. 225-260. 
OCDE. Literacy Skills for the World of Tomorrow: Further Results from PISA 2000, Paris, OECD Publishing, 2003.

OCDE. PISA 2009 Results: Overcoming Social Background. Equity in Learning Opportunities and Outcomes, vol. II, Paris, OECD Publishing, 2010.

OCDE. PISA 2012 Results: Ready to Learn. Students' Engagement, Drive and Self-Beliefs, vol. III, PISA, OECD Publishing, 2013.

Pérez, P. "Sobreeducación en el mercado de trabajo argentino en un periodo de desempleo masivo (1995-2003)", en $7^{\circ}$ Congreso Nacional de Estudios del Trabajo, ASET, 2005.

Reich, M.; D. Gordon, y R. Edwards. "A Theory of Labor Market Segmentation", en The American Economic Review, 63, 2, 1973, pp. 359-365.

Reimers, F. "Educación, desigualdad y opciones de política en América Latina en el siglo XXI", en Revista Latinoamericana de Estudios Educativos, XXX, 2, 2000, pp. 11-42.

Rivas, A., A.Vera y P. Bezem. Radiografía de la educación argentina, Bs. As., Fundación CIPPEC/Fundación Arcor/Fundación Roberto Noble, 2010.

Rivas, A. América Latina después de PISA: lecciones aprendidas de la educación en siete paises 2000-2015, Bs. As., Fundación CIPPEC, 2015, 360 pp.

Rivero, J. "La importancia de la educación en la determinación de la hegemonía. Las teorías de la reproducción", en $L a-$ berinto, 8, 2002. Disponibe en http://laberinto.uma.es/

Rivero, J. "Políticas Educativas y Exclusión: sus Límites y Complejidad", en Revista Electrónica Iberoamericana sobre Calidad, Eficacia y Cambio en Educación, 3, 2, 2005.

Rodríguez, P. "De nuevo, la justicia”, en Revista Latinoamericana de Estudios Educativos, XXXII, 4, 2002, pp. 5-10.

Roemer, J. "Igualdad de Oportunidades", en Isegoría, 18, 1998, pp. 71-87.

Ruiz, G. "La nueva reforma educativa argentina según sus bases legales", en Revista de Educación, 348, 2009, pp. 283-307.

Saviani, D. "Las Teorías de la Educación y el Problema de la Marginalidad en América Latina", en Revista Argentina de Educación, 2, 3, 1983, pp. 7-29. 
Schultz, T. "Capital formation by education", en Journal of Political Economy, 68, 6, 1960, pp. 571-586.

Sen, A. "Equality of What?", en The Tanner Lecture of Human Values, Standford, 1979.

Sendon, M. "Las trayectorias de los egresados de la escuela media en una sociedad mutada", en Revista Mexicana de Investigación Educativa, 10, 24, 2005, pp. 191-219.

SITEAL. Informe Sobre Tendencias Sociales y Educativas en América Latina, 2006. Disponible en http://www.siteal. iipe-oei.org/informe/225/informe-2006

Spence, M. "Job market signaling”, en Quarterly Journal of Economics, 87, 3, 1973, pp. 355-374.

Tedesco, J. y N. López, "Desafíos a la Educación Secundaria en América Latina", en Revista de la CEPAL, 78, 2002, pp. 55-69.

Tenti Fanfani, E., A. Meo y A. Gunturiz. Estado del arte: Escolaridad primaria y jornada escolar en el contexto internacional, Bs. As., IIPE-UNESCO, 2010.

Thurow, L. "Education and economic inequality", en The Public Interest, 28, 1972, pp.66-81.

UNESCO. Education for All: Is the World on Track?, en EFA Global Monitoring Report, Paris, 2002.

UNESCO. Reaching the marginalized. EFA Global Monitoring Report, Paris, 2010.

Veleda, C. Nuevos tiempos para la educación primaria: lecciones sobre la extensión de la jornada escolar, Bs. As., Fundación CIPPEC-Unicef Argentina, 2013, 200 pp.

Veleda, C.; A. Rivas y F. Mezzadra. La construcción de la justicia educativa. Criterios de redistribución y reconocimiento para la educación argentina, CIPPEC-UNICEF-Embajada de Finlandia, Bs. As., 2011.

Wolff, L. y C. De Moura Castro. "Educación secundaria en América Latina y el Caribe. Los retos del crecimiento y la reforma", en Serie de informes técnicos del Departamento de Desarrollo Sostenible, BID, Washington, D. C., 2000.

Young, I. "Equality of Whom? Social Groups and Judgements of Injustice", en Journal of Political Philosophy, 9, 1, 2001, pp. 1-18.

Zaccagnini, M. "Reformas educativas: espejismos de innovación”, en OEI-Revista Iberoamericana de Educación, 2002. Disponible en http://www.rieoei.org/pol_edu4.htm 